\title{
Natural Hair Supplement: Friend or Foe? Saw Palmetto, a Systematic Review in Alopecia
}

\author{
Evyatar Evron $^{\mathrm{a}}$ Margit Juhasz $^{\mathrm{b}} \quad$ Arash Babadjouni $^{\mathrm{c}}$ \\ Natasha Atanaskova Mesinkovska ${ }^{b}$ \\ aDepartment of Medicine, Cedars-Sinai Medical Center, Los Angeles, CA, USA; b Department of Dermatology, \\ University of California, Irvine, Irvine, CA, USA; 'Arizona College of Osteopathic Medicine, Midwestern University, \\ Glendale, AZ, USA
}

\section{Keywords}

Saw palmetto - Natural · Supplement · Hair loss · Alopecia · Androgenetic alopecia - Telogen effluvium

\begin{abstract}
Saw palmetto (SP), a botanical extract with antiandrogenic properties, has gained commercial popularity for its purported benefits on hair regrowth. To summarize published evidence on the efficacy, safety, and tolerability of supplements containing SP in the treatment of alopecia, we conducted a PubMed, Google Scholar, and Cochrane database search using the following terms: (saw palmetto and hair loss), (saw palmetto and androgenetic alopecia), and (saw palmetto and natural supplement and alopecia). Five randomized clinical trials (RCTs) and 2 prospective cohort studies demonstrated positive effects of topical and oral supplements containing SP (100-320 mg) among patients with androgenetic alopecia (AGA) and telogen effluvium. Sixty percent improvement in overall hair quality, $27 \%$ improvement in total haircount, increased hair density in $83.3 \%$ of patients, and stabilized disease progression among 52\% were noted with use of various topical and oral SP-containing supplements. SP was well tolerated and not associated with serious ad-
\end{abstract}

verse events in alopecia patients. Although robust highquality data are lacking, supplements containing SP may be a treatment option for patients with AGA, telogen effluvium, and self-perceived hair thinning. Further large-scale RCTs focusing on the sole contribution of SP to hair growth outcomes are needed to confirm efficacy and determine longterm adverse events.

() 2020 S. Karger AG, Basel

\section{Introduction}

Saw palmetto (SP) is a botanical extract from the berries of the Serenoa repens dwarf tree, native to the subtropical, Southeastern United States [1]. The extract can be prepared as liquid via hot water or supercritical elicitation with carbon dioxide, or as powder via mechanical grinding of raw berries [2]. Due to its antiandrogenic effects, SP has been used as an alternative treatment for benign prostatic hyperplasia (BPH) [3-5], dating back to the 15 th century BCE, Egypt [5].

SP extract is primarily comprised of fatty acids (7095\%) [6], phytosterols such as $\beta$-sitosterol (0.1\%) [6], $\beta$-carotene, vitamin $\mathrm{E}$ derivatives, and polysaccharides;

$\begin{aligned} & \text { karger@karger.com } \\ & \text { www.karger.com/sad }\end{aligned}$
Karger ${ }^{\prime /}$




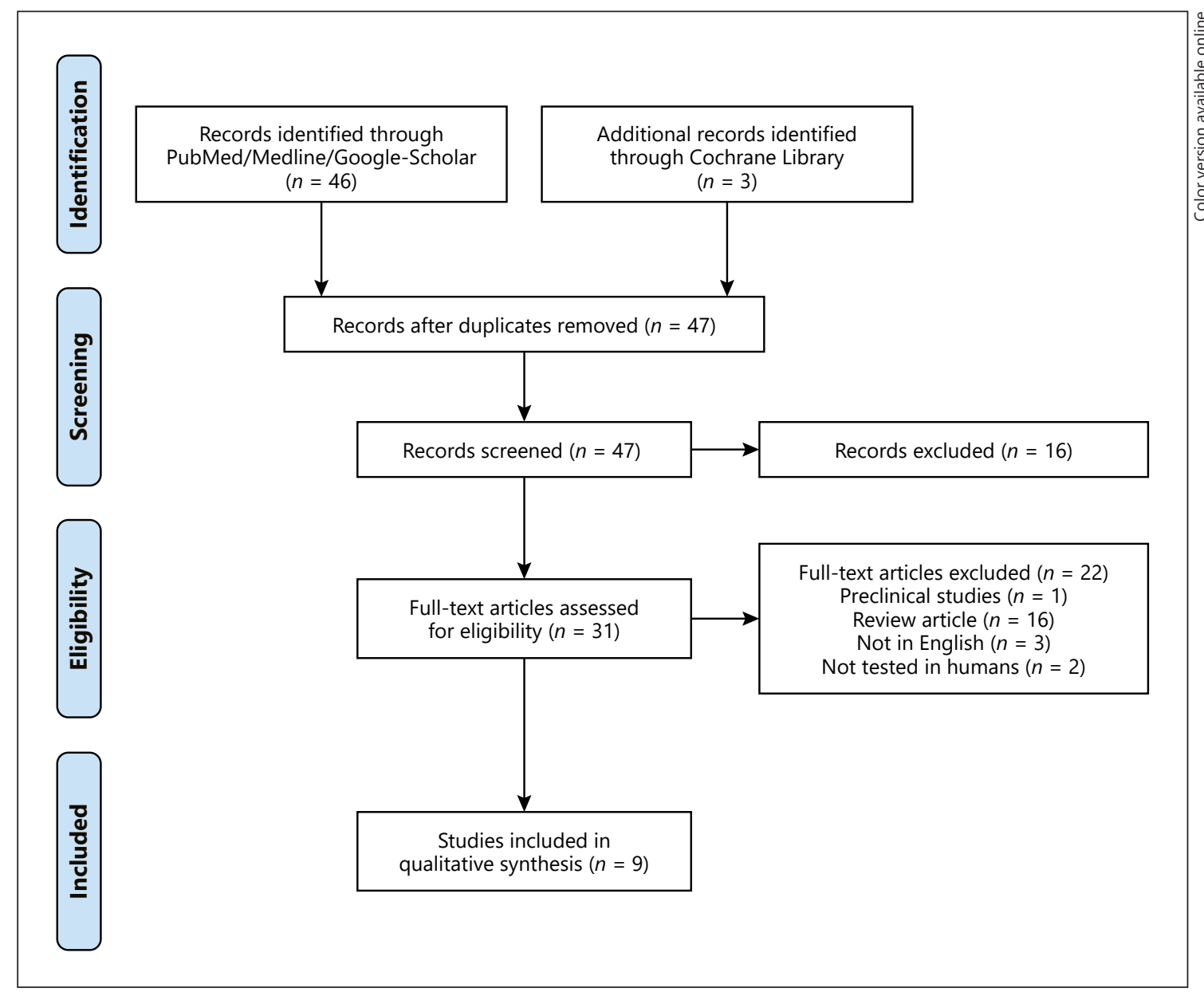

Fig. 1. PRISMA flow diagram depicting the systematic review method to evaluate the effects of SP for the treatment of alopecia.

however, the exact ratios can vary depending on the specific preparation [7]. SP is a competitive, nonselective inhibitor of both $5 a$-reductase isoforms, blocking nuclear uptake of dihydrotestosterone (DHT) and decreasing DHT binding capacity to androgen receptors by nearly $50 \%[8,9]$. SP's fatty acid components directly inhibit enzyme activity [10], aid in the enzyme's selective hormone transformation processes [11], and influence access to cofactors by affecting the enzyme's conformational state [8]. SP also increases the activity of $3 a$-hydroxysteroiddehydrogenase, an enzyme converting DHT to its weaker metabolite, androstanediol [7]. However, also worth noting are the discordant views regarding SP's actual effect on androgen-dependent parameters $[12,13]$ and debatable clinical efficacy in treating BPH $[14,15]$.

SP's antiandrogenic properties, minimal side-effect profile [16], and low drug interaction potential have prompted its use as a complementary alopecia remedy [ 1 , $16,17]$. The extract has been evaluated for the treatment of androgenetic alopecia (AGA) [18-21], telogen effluvium (TE) [22-25], seborrheic dermatitis [26, 27], and facial sebum [28], as a monotherapy or in combination with other supplements, in oral and topical formulations. In this review, we will systematically describe SP extract's efficacy for the treatment of hair loss conditions and associated side effects.

\section{Materials and Methods}

A systematic review was completed searching the National Library of Medicine through PubMed, Google Scholar, and Cochran databases, without date limits, in January 2019, using the following terms: (saw palmetto and hair loss); (saw palmetto and androgenetic alopecia); (saw palmetto and natural supplement and alope- 
cia); and (saw palmetto and telogen effluvium). Inclusion criteria were manuscripts written in English describing randomized clinical trials (RCTs), cohort studies, case series, and case reports on the use of topical or oral supplements containing SP in the treatment of various hair disorders in humans. Exclusion criteria included preclinical studies and review articles. Strength of clinical data was graded according to a modified version of the Oxford Centre for Evidence-Based Medicine.

\section{Results}

The above search generated 9 articles using oral and topical supplements containing SP, with a total of 381 patients, for the treatment of alopecia (Fig. 1). Four RCTs [18-21], 2 prospective cohort studies [24, 29], and 1 case report [30] described the effects of topical or oral SP extract for the treatment of AGA. The efficacy of SP-containing products in treating TE was described in 2 case reports [25, 30], 1 RCT [21], and 1 prospective cohort study [24] (Table 1).

\section{Androgenetic Alopecia}

The first RCT tested the efficacy of a topical SP-containing lotion twice daily, alone and in combination with an oral tablet containing gelatin-cystine 4 times a day, in 60 men and women with AGA over a period of 50 weeks. Five arms were studied with varying combinations of lotion and oral agent versus vehicle and placebo. Hair samples were degreased, dried, counted on a grid, and weighed in an analytical balance at $22^{\circ} \mathrm{C}$. The SP-containing topical demonstrated a time-dependent mean increase in hair count of $17 \%$ by week 10 and $27 \%$ by week 50 , as compared to 6 and $14 \%$ among the vehicle group at weeks 10 and 50, respectively $(p<0.005)$. Hair mass and caliber increased approximately $20 \%$ by week 10 from baseline and $30 \%$ by week 50 using topical SP $(p<0.005)$, versus an approximately $10 \%$ decrease and an $8 \%$ increase amongst the vehicle group at weeks 10 and 50, respectively. The use of topical SP and oral gelatin-cystine supplement caused a further increase of approximately $50 \%$ in all hair growth parameters $(p<0.005)$ when compared to use of either agent alone. Both topical SP and gelatincystine supplement were well tolerated, and no adverse events (AEs) were reported [18].

A small RCT evaluated the efficacy of an oral tablet containing $200 \mathrm{mg}$ of SP extract and an extra $50 \mathrm{mg}$ of $\beta$-sitosterol (which has also been studied singularly for its antiandrogenic effects) versus placebo, taken twice daily in 26 men with mild to moderate AGA over 25 weeks. The primary endpoints of hair loss arrest and qualitative hair

Saw Palmetto, a Systematic Review in Alopecia improvement were assessed objectively by researchers and subjectively by study participants via a standardized 7 -point scale questionnaire. SP demonstrated 60\% "improvement" in hair loss arrest and overall quality versus $11 \%$ among placebo. The active tablet also showed greater conservation of hair density and quality over time, as subjectively assessed by the study participants [19].

The largest RCT to date compared oral 320-mg SPcontaining tablets versus $1-\mathrm{mg}$ finasteride daily in 100 men with AGA over 2 years. Measurement of hair density was assessed by standardized global photography; the effectiveness of the treatment was evaluated with a 7-point clinical score scale as determined by 3 expert dermatologists experienced in the field of alopecia. Notably, $68 \%$ of patients treated with finasteride had higher hair density scores from baseline as compared to $38 \%$ of the SP group $(p<0.05)$, indicating that SP is inferior to finasteride. Although neither treatment was reported to be clinically effective in $10 \%$ of patients, SP had stabilized progression of AGA in 52\% of cases [20].

A 24-week, prospective cohort tested the efficacy of a topical SP-containing lotion applied to the entire scalp daily for the treatment of AGA in 50 men. Study participants also applied a concentrated SP-containing serum dedicated to thinning areas of the scalp for the first 4 weeks. Increased hair count was assessed via macrophotographic techniques using the Canfield photography system; hair restoration (defined by average hair size and terminal hair count) along with change in AGA staging was assessed via the Norwood-Hamilton grading system of pictures. Investigator satisfaction and patient satisfaction were measured via photographic and self-perceived assessment questionnaires, respectively, using a 7-point scale. Total hair count increased at 12 and 24 weeks compared to baseline by 3.4 and $4.9 \%$, respectively, while terminal hair count increased by 21.4 and $74.1 \%$, respectively. Medium-sized and vellus hair counts decreased at 24 weeks compared to baseline by -10.3 and $-25 \%$, respectively. Median AGA stage changed from 4 at baseline to 3 at 24 weeks, with a slight increase of hair over the anterior and vertex scalp, as well as higher patient satisfaction scores noted at study completion [29].

The most recent RCT tested the efficacy of a 100-mg SP-containing food supplement (Lambdapil ${ }^{\circledR}$, ISDIN, Barcelona, Spain) on 35 men with AGA, for 6 months. Outcomes were measured via phototrichogram, where digital images evaluating hair volume and appearance were assessed by dermatologists through a 7-point clinical score scale. Further outcomes were also subjectively evaluated by study participants via completion of self-as- 
Table 1. Summary of clinical investigations using SP extract for the treatment of AGA, TE, and self-perceived hair loss in male and female patients

\begin{tabular}{lll}
\hline Study Disease & $\begin{array}{l}\text { Patient } \\
\text { demo- } \\
\text { graphics }\end{array}$ & rating \\
\hline
\end{tabular}

Androgenetic alopecia

Morganti AGA $\quad 60 \mathrm{M} \quad 1 \mathrm{~b} \quad$ Double-blinded vehicle and placebo-

et al. [18] and $\mathrm{F}$
Significant improvement in hair count at $10 \mathrm{wk}(17 \%)$ No AEs and $50 \mathrm{wk}(27 \%)$ using SP-containing lotion versus reported vehicle ( $\sim 6$ and $14 \%$, respectively)

5 tx arms: SP-containing topical lotion BID and/or an oral supplement containing gelatin-cystine QID versus vehicle and/or placebo for $50 \mathrm{wk}$

\begin{tabular}{lllll}
\hline $\begin{array}{l}\text { Prager } \\
\text { et al. [19] }\end{array}$ & $\begin{array}{l}\text { Mild to } \\
\text { moderate } \\
\text { AGA }\end{array}$ & $26 \mathrm{M}$ & $1 \mathrm{~b}$ & $\begin{array}{l}\text { Double-blinded placebo-controlled } \\
\text { RCT }\end{array}$ \\
\cline { 3 - 5 } & & & $\begin{array}{l}\text { Oral soft-gel supplement (50-mg } \\
\beta \text {-sitosterol, 200-mg SP) versus place } \\
\text { BID for up to 25 wk }\end{array}$ \\
\hline $\begin{array}{l}\text { Rossi } \\
\text { et al. [20] }\end{array}$ & AGA & $100 \mathrm{M}$ & $1 \mathrm{~b}$ & Head-to-head double-blinded RCT
\end{tabular}

\section{Hair mass and caliber significantly improved by $20 \%$ at $10 \mathrm{wk}$ and $30 \%$ at $50 \mathrm{wk}$ using SP-containing lotion versus vehicle $(10 \%$ decrease to $8 \%$ increase,} respectively)

\section{$60 \%$ improvement from baseline in hair loss arrest} and overall quality for the SP group versus placebo $(11 \%)$

Patient-reported conservation of hair density and quality over time for the SP group versus placebo

Nausea, diarrhea unlikely

Significantly higher hair density scores (determined No AEs as $>0$ indicating increased hair density from baseline) reported constipation, related to tx for finasteride $(68 \%)$ versus SP $(38 \%)$

Oral supplement containing 320-mg SP versus 1-mg finasteride daily for $24 \mathrm{mo}$

SP stabilized AGA disease progression in 52\%

Neither tx effective in $10 \%$

\begin{tabular}{lll}
\hline $\begin{array}{l}\text { Wessagowit AGA } \\
\text { et al. [29] }\end{array}$ & $50 \mathrm{M} \quad 4 \quad \begin{array}{l}\text { Prospective cohort } \\
\end{array}$ \\
& $\begin{array}{l}\text { Topical SP-containing lotion to entire } \\
\text { scalp daily for } 24 \mathrm{wk} \text {; concentrated SP- } \\
\text { containing serum to thinning } \\
\text { areas daily for first } 4 \mathrm{wk}\end{array}$
\end{tabular}

\section{Increased total hair count at 12 and 24 wk from baseline (3.4 and $4.9 \%$, respectively)}

Increased terminal hair count at 12 and $24 \mathrm{wk}$ (21.4 and $74.1 \%$, respectively)

Decreased medium-sized and vellus counts at $24 \mathrm{wk}$ from baseline ( -10.3 and $-25 \%$, respectively)

Median AGA stage change from 4 to 3 at $24 \mathrm{wk}$, with mildly increased hair over anterior and vertex scalp

Higher patient satisfaction scores at $24 \mathrm{wk}$ compared to baseline

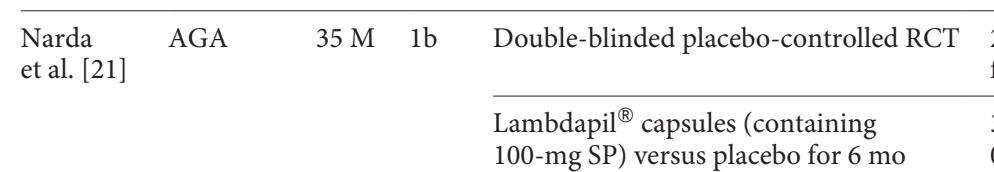

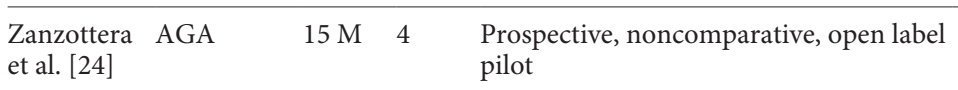
pilot

$23.4 \%$ increase in the anagen/telogen ratio noted from baseline

$3.7 \%$ increase in total anagen hair percentage (vs. $0.8 \%$ decrease), and $3.7 \%$ decrease in total telogen hair percentage (vs. $0.8 \%$ increase) for SP groups versus placebo at $6 \mathrm{mo}$

Increased hair density at 6 mo in $83.3 \%$ of subjects
Cold sensation $(16 \%)$

Mild burning $(12 \%)$

Unpleasant smell $(2 \%)$

Itchy scalp $(2 \%)$

Acne on the forehead (2\%)

No AEs

No AEs

$26.7 \%$ of men with "greatly increased" hair density reported from baseline

93.3\% "general reduction" in hair loss reported by subjects, with $79.0 \%$ reporting "significantly high" reduction

Nutritional supplement containing 83.3\% thicker/bulkier hair

300-mg SP, 2 tab daily for 6 mo
90\% stronger hair and improved combing effect

$88.5 \%$ reduced greasiness

93\% satisfied with results after tx 
Table 1 (continued)

\begin{tabular}{|c|c|c|c|c|c|c|}
\hline Study & Disease & $\begin{array}{l}\text { Patient } \\
\text { demo- } \\
\text { graphics }\end{array}$ & $\begin{array}{l}\text { Quality } \\
\text { rating }\end{array}$ & Study design & Efficacy & Safety \\
\hline \multirow[t]{2}{*}{$\begin{array}{l}\text { Farris } \\
\text { et al. [30] }\end{array}$} & $\begin{array}{l}\text { Unspecified } \\
\text { hair loss } \\
\text { pattern } \\
(n=3)\end{array}$ & & 5 & Case report & \multirow[t]{2}{*}{$\begin{array}{l}\text { Subjective improvement in hair growth and temple } \\
\text { area coverage; also decreased shedding }\end{array}$} & \multirow[t]{2}{*}{$\begin{array}{l}\text { No AEs } \\
\text { reported }\end{array}$} \\
\hline & $\begin{array}{l}\text { Early onset } \\
\text { AGA }(n=1)\end{array}$ & $1 \mathrm{M}$ & & Nutrafol $^{\circledR}$ daily for varying durations & & \\
\hline \multicolumn{7}{|c|}{ Telogen effluvium and self-perceived hair thinning } \\
\hline \multirow[t]{2}{*}{$\begin{array}{l}\text { Pezza } \\
\text { et al. [25] }\end{array}$} & \multirow[t]{2}{*}{ Severe TE } & \multirow[t]{2}{*}{1} & \multirow[t]{2}{*}{5} & Case report & $\begin{array}{l}\text { Significantly improved hair growth and density } \\
\text { (negative pull test) }\end{array}$ & \multirow[t]{2}{*}{$\begin{array}{l}\text { No AEs } \\
\text { reported }\end{array}$} \\
\hline & & & & $\begin{array}{l}\text { Oral supplement containing SP, amino } \\
\text { acids, vitamin E, and iron, } 2 \text { tab daily for } \\
6 \text { mo }\end{array}$ & Increased anagen hairs on trichoscopy & \\
\hline \multirow[t]{2}{*}{$\begin{array}{l}\text { Narda } \\
\text { et al. [21] }\end{array}$} & \multirow[t]{2}{*}{ Acute TE } & \multirow[t]{2}{*}{$35 \mathrm{~F}$} & \multirow[t]{2}{*}{$1 b$} & Double-blinded placebo-controlled RCT & $\begin{array}{l}\text { Improved hair pull test at } 1,3 \text {, and } 6 \text { mo }(9.8,7.5 \text {, and } \\
6.5 \% \text {, respectively) for SP versus placebo }(11.9,10.7 \text {, } \\
\text { and } 8.8 \% \text {, respectively) }\end{array}$ & \multirow[t]{2}{*}{$\begin{array}{l}\text { Bloating } \\
(n=1)\end{array}$} \\
\hline & & & & $\begin{array}{l}\text { Lambdapil }{ }^{\circledR} \text { capsules (containing } \\
100 \text {-mg SP) versus placebo for } 6 \text { mo }\end{array}$ & $\begin{array}{l}\text { Patient-reported increase in hair volume, improved } \\
\text { QOL, and perceived efficacy in the SP group only }\end{array}$ & \\
\hline \multirow[t]{3}{*}{$\begin{array}{l}\text { Zanzottera } \\
\text { et al. [24] }\end{array}$} & FPHL & \multirow[t]{3}{*}{$15 \mathrm{~F}$} & \multirow[t]{3}{*}{4} & \multirow[t]{3}{*}{$\begin{array}{l}\text { Please see the text for discussion of study } \\
\text { design and treatment }\end{array}$} & $\begin{array}{l}33.3 \% \text { of women with "greatly increased" hair density } \\
\text { from baseline }\end{array}$ & \multirow{3}{*}{$\begin{array}{l}\text { Please see the } \\
\text { text for } \\
\text { discussion of } \\
\text { AEs }\end{array}$} \\
\hline & $\mathrm{TE}$ & & & & Please see the text for discussion of other results & \\
\hline & $\begin{array}{l}\text { Stress- } \\
\text { induced hair } \\
\text { loss }\end{array}$ & & & & & \\
\hline \multirow[t]{4}{*}{$\begin{array}{l}\text { Ablon } \\
\text { et al. [31] }\end{array}$} & \multirow[t]{4}{*}{$\begin{array}{l}\text { Self- } \\
\text { perceived } \\
\text { hair } \\
\text { thinning }\end{array}$} & \multirow[t]{4}{*}{$40 \mathrm{~F}$} & \multirow[t]{4}{*}{$1 b$} & \multirow[t]{3}{*}{ Double-blinded placebo-controlled RCT } & $\begin{array}{l}\text { Significant increase in terminal, vellus, and total hair } \\
\text { counts at } 3 \text { mo for the supplement group }(6.8,10.1 \text {, } \\
\text { and } 7.1 \% \text {, respectively) versus placebo }(0.07,-2.9 \text {, } \\
\text { and } 0.4 \% \text {, respectively) }\end{array}$ & \multirow[t]{4}{*}{$\begin{array}{l}\text { No AEs } \\
\text { reported }\end{array}$} \\
\hline & & & & & $\begin{array}{l}\text { At } 6 \text { mo, significant increase in terminal, vellus, and } \\
\text { total hair counts for the supplement group }(10.4,15.7 \text {, } \\
\text { and } 10.8 \% \text {, respectively) versus placebo }(3.5,-2.2 \text {, } \\
0.3 \% \text {, respectively) }\end{array}$ & \\
\hline & & & & & $\begin{array}{l}\text { Higher GHA scores for hair growth ( } 1.08 \text { vs. } 0.08) \\
\text { and hair quality ( } 1.12 \text { vs. } 0.08) \text { for the supplement } \\
\text { group versus placebo, respectively }\end{array}$ & \\
\hline & & & & $\begin{array}{l}\text { Nutrafol }{ }^{\circledR} \text { Women's capsules versus } \\
\text { placebo daily for } 6 \text { mo }\end{array}$ & $\begin{array}{l}\text { Decreased anxiety and improved wellness for the } \\
\text { supplement group versus placebo }\end{array}$ & \\
\hline
\end{tabular}

sessment surveys regarding perceived treatment efficacy. There was a $23.4 \%$ increase from the baseline anagen/ telogen ratio. An additional $3.7 \%$ increase in total anagen hair percentage (vs. $0.8 \%$ decrease), and a $3.7 \%$ decrease in total telogen hair percentage (vs. $0.8 \%$ increase), was noted among the active SP cohort as compared to placebo at 6 months. Patients reported increased hair volume, improved quality of life (QOL), and enhanced self-perceived efficacy using the SP-containing tablet [21]. A prospective, noncomparative cohort tested the efficacy of a nutri- tional compound containing 300-mg SP taken twice daily for 6 months in 15 males with AGA and 15 females with either female-pattern hair loss (FPHL), severe TE, or stress and food-deficiency induced hair loss.

Evaluation of hair loss and hair health parameters was performed via trichoscopy. Global photographs assessing hair density were evaluated by experts on a 7-point scale, and subjective participant efficacy was measured via standardized questionnaires. An increase in hair density at 6 months was noted among $83.3 \%$ of study participants, 
with "greatly increased" density described by $26.7 \%$ of men and $33.3 \%$ of women. $93.3 \%$ of the subjects reported "general reduction" in hair loss, with 79.0\% defining it as "significantly high," $83.3 \%$ reported thicker and bulkier hair, $90.0 \%$ felt their hair was stronger with a better combing effect, and $88.5 \%$ reported reduced greasiness. At the end of the study, $93.0 \%$ of patients were "satisfied" with the results. The supplement was well tolerated [24].

A case series described 3 women with various hair loss patterns and 1 man with early onset AGA, who were successfully treated with Nutrafol ${ }^{\circledR}$ oral supplements $(\mathrm{Nu}$ traceutical Wellness Inc., New York, NY, USA) which include an undisclosed amount of SP extract. Subjective outcomes included enhanced hair growth, improvement in temple area coverage, decreased shedding, and self-reported satisfaction with treatment outcomes, as noted amongst all study participants [30].

\section{TE and Self-Perceived Hair Thinning}

The first case report of a patient with severe TE treated with an oral supplement containing SP, amino acids, vitamin E, and iron taken daily for 6 months demonstrated significant improvement in hair growth and density, as evidenced by a negative pull test and increased anagen hairs on trichoscopy [25]. In another study discussed above, besides the men with AGA, 35 women with acute TE were also treated with Lambdapil ${ }^{\circledR}$ capsules for 6 months. Outcomes measured via the hair pull test resulted in significantly less hair loss at 1,3, and 6 months compared to placebo $(9.8,7.5$, and $6.5 \%$ vs. $11.9,10.7$, and $8.8 \%$, respectively; $p<0.05)$. The female patients also reported increased hair volume, improved QOL, and enhanced self-perceived efficacy with use of the SP-containing supplement. One patient experienced abdominal bloating, resulting in premature termination from the study [21]. In the study by Zanzottera et al. [24], 15 women with FPHL, TE, or stress-induced hair loss were treated with a nutritional supplement containing $300 \mathrm{mg}$ of SP for 6 months with positive results using the abovementioned outcome evaluation techniques.

A recent RCT evaluated the use of an oral Nutrafol ${ }^{\circledR}$ Women's capsule taken 4 times daily for 6 months, to strengthen and promote hair growth in 40 healthy adult women with self-perceived thinning. Increments in total hair counts, blinded investigator Global Hair Assessment (GHA) scales, changes in terminal hair diameter, and bundle measurements were all assessed via phototrichograms obtained though macrophotography analysis. A significant increase in terminal, vellus, and total hair counts was noted at 3 months in the supplement group
$(6.8,10.1$, and $7.1 \%$, respectively) compared to placebo $(0.07,-2.9$, and $0.4 \%$, respectively). Similar outcomes among the treatment group were also noted at 6 months $(10.4,15.7$, and $10.8 \%$, respectively). Higher GHA scores for hair growth (1.08 vs. 0.08$)$ and hair quality (1.12 vs. $0.08)$, along with decreased anxiety and improved wellness parameters, were noted among those receiving SPcontaining supplements [31].

\section{Adverse Events}

The majority of reported AEs with use of oral SP for alopecia are mild and most commonly gastrointestinal in nature, including nausea, constipation, and diarrhea [2, $16,19,26]$. Additionally, likely associated with its hormonal effects, SP has been reported to cause vasomotor symptoms in premenopausal females and was suspected as a cause of early menarche in young girls $[22,32]$. A report by Miroddi et al. [32] described hot flashes in an 11 -year-old girl that appeared after 2 months of treating TE with a food supplement containing SP. The hot flashes ceased when the product was discontinued; however, 45 days after cessation the girl experienced menarche. Another report by Morabito et al. [22] also described similar vasomotor symptoms in a 10 -year-old girl after 3 months of treating hirsutism with a food supplement containing $320 \mathrm{mg}$ of SP extract. As in the prior report, here too the symptoms ceased upon discontinuation of the supplement and the girl experienced menarche shortly thereafter. Topical agents containing SP extract have also been associated with minor AEs including cold sensation, mild burning, unpleasant smell, itchy scalp, acne on the forehead, and allergic contact dermatitis $[33,34]$. Although we are currently unaware of any recommendations against use of SP-containing supplements for hair loss among adult men or women with child bearing potential, as with any unregulated substance, patients are advised to seek specific recommendations from their primary care provider and/or dermatologist prior to initiation of use.

\section{Discussion}

Hair loss is associated with significant consequences affecting body image, self-esteem, emotional well-being, and QOL [35], possibly even leading to psychiatric morbidity such as anxiety and depression $[36,37]$. While minoxidil and finasteride remain the only United States Food and Drug Administration (FDA)-approved and most widely used therapies for pattern hair loss [38], un- 
desired side effects have prompted the search for alternative therapies [39]. SP is a key ingredient in many overthe-counter supplements marketed for hair regrowth; however, limited data exist to support its efficacy in various alopecias or to better delineate its side-effect profile.

The vast majority of data pertaining to SP's efficacy, antiandrogenic properties in vitro, and side-effect profile are derived from studies on $\mathrm{BPH}[8,9]$ and treatment of urinary symptoms in vivo [3-5]. However, many of these findings have been called into question, given subsequent trials showing no effects on androgen-dependent parameters when SP is compared to traditional antiandrogenic agents such as finasteride $[12,13]$. Despite numerous reports regarding SP's clinical efficacy, comprehensive meta-analyses have failed to demonstrate significant improvement in $\mathrm{BPH}$ symptoms or objective disease parameters, thus casting doubt on SP's previously attributed antiandrogenic properties $[14,15]$.

Clinical evidence regarding the efficacy of SP-containing products to treat hair loss is limited. SP has shown promising results in murine models, with hair regrowth mediated through transforming growth factor- $\beta$ and mitochondrial signaling pathways [40]. Additionally, in vitro models have demonstrated SP's ability to inhibit inflammatory gene expression in human keratinocytes, suggesting a multifaceted mechanism for the treatment of AGA, in addition to its proposed antiandrogenic properties [41]. The mechanism in which SP instigates hair growth in TE is not entirely clear. A possible explanation may be secondary to its anti-inflammatory properties, or to $\beta$-sitosterol's purported angiogenic effects, stimulating vascular endothelial growth factor in vitro and promoting neovascularization in vivo [42].

Several human studies have demonstrated modest hair regrowth using oral and topical SP-containing products among patients with AGA, FPHL, TE, and self-perceived hair thinning. Improvement in total hair count ranging from 3.4 to $27 \%[18,29]$, increased hair density in up to $83.3 \%$ of patients [24], $60 \%$ improvement in overall hair quality [19], and stabilized disease progression among $52 \%$ of patients [20] were noted with use of various SPcontaining oral supplements, topical lotions, and/or serums.

However, almost all current formulations containing SP also contain other vitamins, minerals, or chemical additives, making it challenging to discern the exact extent of SP's contribution to the observed clinical findings. Additionally, among the RCTs presented there were several methodological flaws, such as inadequate statistical analyses [18], limited sample size [19], lack of appropriate

Saw Palmetto, a Systematic Review in Alopecia comparison groups $[24,29]$, qualitative rather than quantitative measures of hair regrowth [30], and conflicts of interest with sponsorship by the pharmaceutical industry [21]. In the only head-to-head RCT comparing SP-containing tablets to systemic finasteride, moderate efficacy in hair regrowth was demonstrated among the SP group; however, overall outcomes were inferior to finasteride [20]. Clinical trials involving patients with TE were only conducted using female patients, and results were described qualitatively. Currently, there is a trial (NCT03052413) assessing the efficacy of an SP-containing supplement in women with mild to moderate hair loss; however, results are pending [43].

SP is well tolerated, and although it has not been associated with serious AEs in alopecia patients [16], more grave effects in other clinical settings have been described. Due to its hormonal effects, SP has the potential to cause gynecomastia [16], decrease libido [16], and reduce prostate serum antigen (PSA) levels, thereby necessitating vigilance not to miss early prostate cancer diagnosis [26]. Other reported AEs include rhinitis [16], intraoperative hemorrhage [44], hepatitis and pancreatitis [45, 46], loss of iris tone and intraoperative floppy-iris syndrome (IFIS) [47], and even 1 case of hypokalemia leading to cardiac arrest and death [16]. Further long-term studies are required for reliable safety assessment.

Limitations of this review include lack of meta-analysis, which was not performed owing to absent standardization of results between studies, and a low number of high-quality RCTs. Additionally, the exclusive impact of SP could not be adequately assessed, as many supplements were comprised of multiple, active ingredients, and several studies failed to adequately specify the precise amount of SP or the exact formula content used. The absence of standardized measurement tools used to assess hair growth in each study is also a considerable limitation given the significant expected variability in outcomes directly correlating with the preferred method of evaluation.

\section{Conclusion}

Although robust efficacy data are lacking, SP extract in either topical or oral formulations may have a role in the treatment of hair loss disorders such as AGA or TE, demonstrating modest improvement in hair regrowth. However, as many of the current trials are lacking in quality (descriptive, qualitative measures, small sample sizes, inadequate product content description, long-term results, 
etc.), the majority of outcomes should be interpreted with caution. Additionally, it is worth emphasizing that in the only head-to-head trial conducted between SP and finasteride, it was SP that demonstrated inferiority. Further independent and high-quality RCTs are necessary in order to better delineate the efficacy of SP in alopecia disorders and long-term AEs.

\section{Conflict of Interest Statement}

The authors have no conflicts of interest to declare.

\section{Funding Sources}

The authors have no financial interest to disclose. The authors did not receive funding for this research.

\section{Author Contributions}

This review is the original work of Dr. Evyatar Evron, who was involved in reviewing the literature, subsequent analysis of the collected data, and writing of the final report. Dr. Natasha Atanaskova Mesinkovska, Dr. Margit Juhasz, and Mr. Arash Babadjouni were involved in the development of the initial study design and protocol as well as in the editing of this paper.

\section{References}

1 Gordon AE, Shaughnessy AF. Saw palmetto for prostate disorders. Am Fam Physician. 2003;67(6):1281-3.

2 Zeiger E, Tice R. Saw palmetto (Serenoa repens) and one of its constituent sterols-sitosterol. Review of toxicological literature. Nov 1997.

3 Bach D, Ebeling L. Long-term drug treatment of benign prostatic hyperplasia: results of a prospective 3-year multicenter study using Sabal extract IDS 89. Phytomedicine. 1996; 3(2):105-11.

4 Gerber G. Saw palmetto for the treatment of men with lower urinary tract symptoms. J Urol. 2000;163(5):1408-12.

5 Wilt TJ, Ishani A, Stark G, MacDonald R, Lau J, Mulrow C. Saw palmetto extracts for treatment of benign prostatic hyperplasia: a systematic review. JAMA. 1998;280(18):1604-9.

6 Booker A, Suter A, Krnjic A, Strassel B, Zloh $M$, Said M, et al. A phytochemical comparison of saw palmetto products using gas chromatography and (1) H nuclear magnetic resonance spectroscopy metabolomic profiling. J Pharm Pharmacol. 2014;66(6):811-22.

7 Chatterjee S, Agrawala S. Saw palmetto (Serenoa repens) in androgenic alopecia, an effective phytotherapy. NISCAIR Online Periodicals Repository. Dec 2003.

8 Iehlé C, Délos S, Guirou O, Tate R, Raynaud JP, Martin PM. Human prostatic steroid 5 alpha-reductase isoforms--a comparative study of selective inhibitors. J Steroid Biochem Mol Biol. 1995;54(5-6):273-9.

9 Sultan C, Terraza A, Devillier C, Carilla E, Briley M, Loire C, et al. Inhibition of androgen metabolism and binding by a liposterolic extract of "Serenoa repens B" in human foreskin fibroblasts. J Steroid Biochem. 1984; 20(1):515-9.

10 Liang T, Liao S. Inhibition of steroid 5 alphareductase by specific aliphatic unsaturated fatty acids. Biochem J. 1992;285(Pt 2):557-62.
11 Sargent NSE, Habib FK. Partial purification of human prostatic $5 \alpha$-reductase (3-oxo- $5 \alpha$ steroid: NADP+ 4-ene-oxido-reductase; EC 1.3.1.22) in a stable and active form. J Steroid Biochem Mol Biol. 1991;38(1):73-7.

12 Strauch G, Perles P, Vergult G, Gabriel M, Gibelin B, Cummings S, et al. Comparison of finasteride (Proscar) and Serenoa repens (Permixon) in the inhibition of 5-alpha reductase in healthy male volunteers. Eur Urol. 1994;26(3):247-52.

13 Carraro, JC, Raynaud JP, Koch G, Chisholm GD, Di Silverio F, Teillac P, et al. Comparison of phytotherapy (Permixon) with finasteride in the treatment of benign prostate hyperplasia: a randomized international study of 1,098 patients. Prostate. 1996;29(4):231-40; discussion 241-2.

14 Dedhia RC, McVary KT. Phytotherapy for lower urinary tract symptoms secondary to benign prostatic hyperplasia. J Urol. 2008; 179(6):2119-25.

15 Tacklind J, Macdonald R, Rutks I, Stanke JU, Wilt TJ Serenoa repens for benign prostatic hyperplasia. Cochrane Database Syst Rev. 2012;12:Cd001423.

16 Agbabiaka TB, Pittler MH, Wider B, Ernst E Serenoa repens (saw palmetto): a systematic review of adverse events. Drug Saf. 2009; 32(8):637-47.

17 Markowitz JS, Donovan JL, Devane CL, Taylor RM, Ruan Y, Wang JS, et al. Multiple doses of saw palmetto (Serenoa repens) did not alter cytochrome P450 2D6 and 3A4 activity in normal volunteers. Clin Pharmacol Ther. 2003;74(6):536-42.

18 Morganti P, Fabrizi G, James B, Bruno C. Effect of gelatin-cystine and Serenoa repens extract on free radicals level and hair growth. J Appl Cosmetol. 1998;16:57-64.

19 Prager N, Bickett K, French N, Marcovici G. A randomized, double-blind, placebo-controlled trial to determine the effectiveness of botanically derived inhibitors of 5-alpha-reductase in the treatment of androgenetic alopecia. J Altern Complement Med. 2002;8(2): $143-52$.
20 Rossi A, Mari E, Scarno M, Garelli V, Maxia C, Scali E, et al. Comparitive effectiveness of finasteride vs Serenoa repens in male androgenetic alopecia: a two-year study. Int J Immunopathol Pharmacol. 2012;25(4):1167-73.

21 Narda M, Aladren S, Cestone E, Nobile V. Efficacy and safety of a food supplement containing L-cystine, Serenoa repens extract and biotin for hair loss in healthy males and females. A prospective, randomized, doubleblinded, controlled clinical trial. J Cosmo Trichol. 2017;3(127):2.

22 Morabito P, Miroddi M, Giovinazzo S, Spina E, Calapai G. Serenoa repens as an endocrine disruptor in a 10-year-old young girl: a new case report. Pharmacology. 2015;96(1-2):413.

23 Gómez Grau E, Lladós Sevilla M, Mira J, Vivancos F. Eficacia de un complemento alimenticio con serenoa serrulata y tocotrienol-tocoferol frente a la alopecia androgenética y el efluvio telógeno femeninos: a propósito de un estudio piloto. J Rev Argent Dermatosifilol. 2015;96(1):43-55.

24 Zanzottera F, Bizzaro G, Michelotti A, Nobile V. Efficacy of a nutritional supplement, standardized in fatty acids and phytosterols, on hair loss and hair health in both women and men. J Cosmo Trichol. 2017;3(121):2.

25 Pezza M, Carlomagno V, Casucci G. Telogen effluvium treated with Serenoa repens supplement. J Senses Sci. 2014;1(1).

26 Murugusundram S, Repens S. Serenoa repens: does it have any role in the management of androgenetic alopecia? J Cutan Aesthet Surg. 2009;2(1):31-2.

27 Togni S, Maramaldi G, Meneghin M, Giacomelli L. Effective oral treatment for scalp disorders: results from a double blind, placebocontrolled study. Esperienze Dermatol. 2016; 8:187-91.

28 Dobrev H. Clinical and instrumental study of the efficacy of a new sebum control cream. J Cosmet Dermatol. 2007;6(2):113-8. 
29 Wessagowit V, Tangjaturonrusamee C, Kootiratrakarn T, Bunnag T, Pimonrat T, Muangdang N, et al. Treatment of male androgenetic alopecia with topical products containing Serenoa repens extract. Australas J Dermatol. 2016;57(3):e76-82.

30 Farris PK, Rogers N, McMichael A, Kogan S. A novel multi-targeting approach to treating hair loss, using standardized nutraceuticals. J Drugs Dermatol. 2017;16(11):S141-8.

31 Ablon G, Kogan S. A six-month, randomized, double-blind, placebo-controlled study evaluating the safety and efficacy of a nutraceutical supplement for promoting hair growth in women with self-perceived thinning hair. J Drugs Dermatol. 2018;17(5):558-65.

32 Miroddi M, Carnì A, Mannucci C, Moleti M, Navarra M, Calapai G. Hot flashes in a young girl: a wake-up call concerning Serenoa repens use in children. Pediatrics. 2012;130(5): e1374-6.

33 Cabrita SF, Silva R, Correia MP. Allergic contact dermatitis due to glycyrrhizic acid as an ingredient of a hair restorer. Contact Derm. 2003;49(1):46.

34 Sinclair RD, Mallari RS, Tate B. Sensitization to saw palmetto and minoxidil in separate topical extemporaneous treatments for androgenetic alopecia. Australas J Dermatol. 2002;43(4):311-2.
35 Reid EE, Haley AC, Borovicka JH, Rademaker A, West DP, Colavincenzo M, et al. Clinical severity does not reliably predict quality of life in women with alopecia areata, telogen effluvium, or androgenic alopecia. J Am Acad Dermatol. 2012;66(3):e97-102.

36 Schmitt JV, Ribeiro CF, Souza FH, Siqueira EB, Bebber FR. Hair loss perception and symptoms of depression in female outpatients attending a general dermatology clinic. An Bras Dermatol. 2012;87(3):412-7.

37 Grimalt R. Psychological aspects of hair disease. J Cosmet Dermatol. 2005;4(2):142-7.

38 Rogers NE, Avram MR. Medical treatments for male and female pattern hair loss. J Am Acad Dermatol. 2008. 59(4):547-66; quiz 567-8.

39 Lourith N, Kanlayavattanakul M. Hair loss and herbs for treatment. J Cosmet Dermatol. 2013;12(3):210-22.

40 Zhu HL, Gao YH, Yang JQ, Li JB, Gao J Serenoa repens extracts promote hair regeneration and repair of hair loss mouse models by activating TGF- $\beta$ and mitochondrial signaling pathway. Eur Rev Med Pharmacol Sci. 2018;22(12):4000-8.
41 Chittur S, Parr B, Marcovici G. Inhibition of inflammatory gene expression in keratinocytes using a composition containing carnitine, thioctic acid and saw palmetto extract. Evid Based Complement Alternat Med. 2011; 2011:985345.

42 Moon EJ, Lee YM, Lee OH, Lee MJ, Lee SK, Chung $\mathrm{MH}$, et al. A novel angiogenic factor derived from Aloe vera gel: beta-sitosterol, a plant sterol. Angiogenesis. 1999;3(2):117-23.

43 ClinicalTrials.gov [Internet]. Sadick Research Group: National Library of Medicine (US). Feb 2017. Identifier NCT03052413, Study to evaluate a nutraceutical supplement for treatment of hair loss and thinning in females. Available from: https://ClinicalTrials.gov/ show/NCT03052413.

44 Cheema P, El-Mefty O, Jazieh AR. Intraoperative haemorrhage associated with the use of extract of Saw Palmetto herb: a case report and review of literature. J Intern Med. 2001; 250(2):167-9.

45 Jibrin I, Erinle A, Saidi A, Aliyu ZY. Saw palmetto-induced pancreatitis. South Med J. 2006;99(6):611-2.

46 Wargo KA, Allman E, Ibrahim F. A possible case of saw palmetto-induced pancreatitis. South Med J. 2010;103(7):683-5.

47 Yeu E, Grostern R. Saw palmetto and intraoperative floppy-iris syndrome. J Cataract Refract Surg. 2007;33(5):927-8. 